\title{
Orofaciodigital syndrome type 5
}

INSERM

\section{Source}

INSERM. (1999). Orphanet: an online rare disease and orphan drug data base.

Orofaciodigital syndrome type 5. ORPHA:2919

Oral-facial-digital syndrome, type 5 is characterized by median cleft of the upper lip,

postaxial polydactyly of hands and feet, and oral manifestations (duplicated frenulum). 